\title{
Adaptation of VSC-HVDC Connected DFIG Based Offshore Wind Farm to Grid Codes: A Comparative Analysis
}

\author{
Seyed Saed Heidary Yazdi*, Jafar Milimonfared and Seyed Hamid Fathi
}

Department of Electrical Engineering, Amirkabir University of Technology, Tehran, Iran

\begin{abstract}
Lack of synchronism between VSC-HVDC (Voltage Source Converter - High Voltage Direct Current) connected offshore wind farm and onshore grid leads to immunity of wind turbines to grid contingencies. Focusing on DFIG (Doubly Fed Induction Generator) based wind farms; this paper has presented a univalent control structure based on inertial and primary frequency response in which DC link voltage is utilized as synchronization interface. Based on the presented structure, four approaches based on the communication system, frequency, voltage and combined frequency and voltage modulation are utilized and compared to inform the onshore grid status to individual wind turbines. Considering Kondurs two area power system, results have revealed that all four approaches have similar ability (with negligible error) in offering inertial and primary frequency response to improve slow network oscillations. On the other hand, voltage and combined frequency and voltage modulation approaches have the ability to satisfy Fault Ride Through (FRT) requirements thanks to superior dynamics. However, communication and frequency modulation approaches lose that ability as communication and frequency measurement delays increase respectively. It has been concluded that combined frequency and voltage modulation, as the superior approach, has advantages like minimum FRT DC voltage profile increase and deviation from operating point after the fault, the minimum imposition of electrical and mechanical stress on DFIG and preservation of prevalent control structure thanks to appropriate dissociation between slow and fast dynamics.
\end{abstract}

C2019. CBIORE-IJRED. All rights reserved Keywords: Grid codes, VSC-HVDC transmission line, offshore wind farm, doubly fed induction generator, voltage source converter, primary frequency response, inertial frequency response, fault ride through

Article History: Received Dec $8^{\text {th }} 2017$; Received in revised form July $16^{\text {th }} 2018$; Accepted December $15^{\text {th }} 2018$; Available online

How to Cite This Article: Yazdi, S.S.H., Milimonfared, J. and Fathi, S.H. (2019). Adaptation of VSC-HVDC Connected DFIG Based Offshore Wind Farm to Grid Codes: A Comparative Analysis. Int. Journal of Renewable Energy Development, 8(1), 91-101. https://doi.org/10.14710/ijred.8.1.91-101

\section{Introduction}

Commissioning of offshore wind farms with a distance more than $60 \mathrm{~km}$ from the shore is growing in Europe. Growing increase in wind power penetration factor (e.g. $\% 42$ and \%22 in Denmark (Energinet, 2014) and Spain (Red Eléctrica de España, 2015)) decreases onshore wind farms potentials. Higher wind speed and uniform wind profile along with reduced visual and acoustic noises are incentives to install offshore wind farms (Yazdi et al., 2014). By the end of 2014, 84 offshore wind farms with total capacity of $11 \mathrm{GW}$ are installed in 11 European countries (Association, 2016).

Selection of appropriate transmission technology puts technical and economic challenges forward. Voltage Source Converter based High Voltage Direct Current (VSC-HVDC) transmission attracts both industry and academia thanks to significant advantages and alleviating rival candidates shortcomings. For instance, charging current challenge is not an issue, unlike HVAC transmission. Moreover, it is possible to transmit a same amount of power with two conductors assuming a similar insulation to HVAC transmission. Also, skin effect, corona, and dielectric losses are reduced substantially.
Therefore, HVDC transmission is the economic choice for offshore wind farms with a distance more than $25-50 \mathrm{~km}$ from the shore despite offering an extra degree of freedom (Xu et al., 2007).

Grid code compatibility of VSC-HVDC connected offshore wind farms is subject to basic research. These codes stipulate control and regulatory capabilities similar to conventional power plants to ensure wind power plant stability and its consistent connection to the grid during contingencies and therefore secure, reliable and economic operation of power system (Tsili and Papathanassiou, 2009). However, wind turbines are immune to grid contingencies (e.g. short circuit fault and frequency events) in the considered system due to lack of synchronism between them. However, modern wind turbines are programmed to provide Fault Ride Through (FRT) and inertial and primary frequency maneuvers according to grid codes (D'1az-Gonz'alez et al., 2016). Moreover, short circuit fault can lead to the power imbalance in HVDC link and excessive DC overvoltage due to the abrupt decrease of power injected into the grid (Shoulaie and Jafarabadi, 2005). Hence, grid code compatibility is not satisfied. Different approaches have been proposed in the literature to surmount the

\footnotetext{
* Corresponding author: saedheidary@aut.ac.ir
} 
noncompliance and modulating the wind farm response. Communication infrastructure has been used in the first approach (\#1) to transmit information (e.g onshore grid status) between Grid Side Converter (GSC), Wind Power Plant Side Converter (WPPSC) and Wind Turbine (WT)s. The information might be gathered from the local measurement of grid status at GSC or estimated using WPPSC dc voltage and current measurement. DC voltage level is modulated by WPPSC in the latter case to make WPPSC aware from grid status. Communication infrastructure is utilized afterward to inform individual WTs (Ramtharan et al., 2009). Therefore, fiber optic cables length is reduced significantly. Focusing on frequency events in the onshore grid, first approach has been successfully implemented in (Pipelzadeh et al., 2012) to excite inertial response and in (Miao et al., 2010) and (Nanou and Papathanassiou, 2016) to excite combined inertial and primary frequency response. Considering FRT operation, the situation has been declared to wind turbines (Ramtharan et al., 2009), (Foster et al., 2008). Supplementary control loops have utilized two different approaches (torque reference reduction in machine side converter or power reference reduction in grid side converter which is a faster approach) to reduce the injected wind power and hence have limited the transmission links DC voltage to 1.13 pu and 1.19 pu respectively (Ramtharan et al., 2009). Communication delays, limited data transfer rate, and reliability concerns have led to the incorporation of dissipating chopper in this approach (Nanou and Papathanassiou, 2015). Therefore, the chopper capacity is reduced significantly (up to 50\%) even in presence of high communication delays.

Shortcomings of communication-based approach (especially in FRT condition) and fast response of wind turbines to electrical contingencies (in comparison with alteration of electrical references) have resulted in the introduction of wind farm frequency modulation approach (\#2) (Foster et al., 2008). In this approach, an intentional frequency variation proportional to onshore grid frequency contingency (or fault) is applied to wind farm in order to excite wind turbines inertial and primary frequency response. Taking frequency events into account, (Phulpin, 2012) has formulated frequency modulation and (Nanou et al., 2015) and (Silva et al., 2012) have asserted successful function of this approach in providing inertial response in HVDC transmission system and combined inertial and primary frequency response in Multi-Terminal DC (MTDC) transmission system respectively. This method has been combined with utilizing energy stored in transmission link capacitors to further provide inertial response in (Liu and Chen, 2015) and (Junyent-Ferr et al., 2015). (Sanz et al., 2015) has defined appropriate reference for modulation of wind farms frequency and provision of inertial response by calculation of weighted total variations of onshore grids frequencies. Taking FRT condition into account, the injected wind power is reduced quickly by the application of frequency modulation to surmount power imbalance in transmission link and clamp DC voltage to $1.3 \mathrm{pu}, 1.5 \mathrm{pu}$, $1.4 \mathrm{pu}$ and $1.2 \mathrm{pu}$ respectively (Xu et al., 2007), (Feltes et al., 2009), (Nanou and Papathanassiou, 2016) and (Nanou et al., 2015). This method has been also applied to MTDC systems (Hu et al., 2013), (Silva et al., 2014) and experimental results is revealed in (Adeuyi et al., 2015).The fast dynamic of this method is highly questionable due to limited permissible frequency variation rate, frequency measurement delay and limited bandwidth of wind turbines controllers. These challenges are also revealed in (Xu et al., 2007), (Feltes et al., 2009), (Nanou and Papathanassiou, 2016) and (Nanou et al., 2015) since frequency modulation has failed to clamp the transmission link DC voltage to 1.2 p.u.

Debility of frequency modulation approach in FRT condition, have resulted in the introduction of wind farm voltage modulation strategy (\#3). Similar to the previous approach, an intentional voltage variation proportional to onshore grid fault (or frequency contingency) level is applied to the wind farm to force wind turbines to reduce the injected power even without relying on internal controllers. This approach has been successfully applied to Permanent Magnet Synchronous Generator (PMSG) based wind farms, however, large short circuit currents were revealed (Silva et al., 2014). This foible is even more challenging considering Doubly Fed Induction Generator (DFIG) which is well known with its high amplitude of short circuit current that contains a DC component. Therefore (Feltes et al., 2009) and (Erlich et al., 2014) have demagnetised DFIG wind farm in a controlled fashion prior to applying voltage modulation approach in order to prevent excessive electrical and mechanical stresses. Moreover (Silva et al., 2014) has utilized the idea proposed in (Yang et al., 2012) to reduce the DFIGs short circuit current amplitude.

Some parts of practical limitations available in wind turbines (Miller et al., 2003) and power system including limited output power gradient $( \pm 0.45 \mathrm{pu} / \mathrm{s})$, maximum Rate Of Change Of Frequency (ROCOF) $( \pm 2 \mathrm{~Hz} / \mathrm{s})$, communication delays, limited pitch angle variation rate ( $\pm 10 \mathrm{deg} / \mathrm{s})$, minimum and maximum output power of WT (-0.05 pu up to $1 \mathrm{pu}$ ) and appropriate sharing of current capacity between active and reactive components (Engelhardt et al., 2011) are neglected in a significant proportion of previous researchs. On the other hand, most of the proposed approaches have focused on the PMSG based wind farms and optimized to a special contingency. Moreover, some of the considered assumptions are not consistent with modern grid codes. Therefore, the successful function can not be generalized.

Accordingly, a comprehensive research is needed that assesses the application of three major approaches along with hybrid approaches to DFIG based wind farms in a univalent control structure. This structure should be based on assumptions and requirements of standard grid codes (e.g FRT maneuver, inertial and primary frequency response). This research (which is done in this paper) should consider practical limitations of wind turbines and power system along with constraints associated with major approaches like communication delay, maximum ROCOF, and reasonable voltage reduction.

This paper is structured as below. The standard assumptions and requirements of grid codes are investigated in section II. The investigated system is described in section III. Univalent control structure and implementation of different approaches in WTs and HVDC converters are described in section IV. Simulation results are depicted in section V. Section VI draws the conclusions.

\section{Standard grid code requirements}

The grid code requirements specified by Transmission System Operator (TSO)s could be classified in 5 group (Mohseni and Islam, 2012). FRT requirements, post fault 
active and reactive power control and frequency control are investigated in this paper. Power system short circuit fault makes wind turbines to experience severe voltage dip and even instability. Probable disconnection of wind turbines leads to a significant reduction of power generation. Moreover, in VSC-HVDC lines, there is a risk of DC link over-voltage due to assigning priority of GSC current capacity to reactive component and intense decline of power injection to the grid. The appeared DC over voltage should be limited to $1.2 \mathrm{pu}$ in order to protect DC capacitors, semiconductors and etc. On the other hand, increased penetration of wind power production and gradual retirement of conventional wind power plants associates regulation and stability of power system to wind farms demeanor.

To surmount the challenges, modern GCs ordain FRT requirements. These requirements coerce WTs to stay connected to the grid, assign the priority of GSC to reactive component, provide extra reactive current proportional to voltage dip and return to the previous operating point after fault clearance. For instance, maintaining the connection to the grid should be assured even during \%100 voltage dip up to $150 \mathrm{~ms}$ according to German grid code. Moreover, $2 \mathrm{pu} / \Delta \mathrm{V}$ slope is considered for extra FRT reactive current injection. Also, injected active power should return to the previous operating point preserving $0.2 \mathrm{pu} / \mathrm{s}$ ramp rate. On the other hand, WTs is coerced to provide inertial (to decrease the rate of frequency change and prevent triggering power system protection) and primary (to maintain stability and confine steady state frequency deviation) frequency response. For example, \%5 droop control is required to provide primary frequency control in German grid code, however, $0.2 \mathrm{~Hz}$ dead band is considered in over frequency events due to strong nature of German grid. Also, ENTSO-E persuades European TSOs to force WPPs to provide inertial frequency response (ENTSO-E, 2015).

\section{The investigated system}

Single line diagram of the investigated system is shown in Fig. 1. It is comprised of $400 \mathrm{MW}(80 \times 5 \mathrm{MW}) \mathrm{WPP}$ employing DFIGs. Aggregated model (García et al., 2015) is implemented to reduce computational burden. WT model consists of the aerodynamic model (Jonkman et al.,
2009), 2-mass drive train, pitch angle control (Miller et al., 2003) and vector controlled DFIG (Hu et al., 2011). Series braking protection system (Lu et al., 2013) and DC chopper (Nasiri et al., 2015) are implemented at Rotor Side Converter (RSC) and DC link respectively to prevent high short circuit currents and DC over voltage. The simulated WPP is connected to HVDC converter through LV/MV transformer, $2 \mathrm{~km}$ undersea cable (with specifications indicated in (Chaudhary et al., 2009)) and MV/ HV transformer. HVDC converters are connected via a $\pm 150 \mathrm{kV}, 100 \mathrm{~km}$ undersea cable (Nanou and Papathanassiou, 2016). Electro-Magnetic Transient (EMT) models are implemented that truly represent VSC switching harmonics. DC chopper is installed in HVDC link to alleviate FRT imbalance. The structure and control logic of DC chopper is explored in (Nasiri et al., 2015). HVDC GSC is connected to a strong AC grid (short circuit capacity $=20000 \mathrm{MVA}$ ) via transformer. However, Kondurs two area power system is considered as the test system in investigating frequency events (Klein et al., 1991) (Fig .2). Moreover, averaged model is implemented to represent VSCs. The symmetric two area power system is comprised of four thermal plants that represent power system oscillations. Each power plant is equipped with the governor (\%5 droop controller for primary frequency control), IEEE type 1 excitation system and power system stabilizer. The simulations are carried out in MATLAB/Simulink environment. A brief list of parameters is shown in the appendix.

\section{Univalent control structure}

\subsection{Control of HVDC converters}

\subsubsection{GSC control}

GSC plays a critical role in maintaining the stability and GC compatibility of HVDC link. The main role of GSC is to regulate the DC link voltage in order to preserve power balance.

Moreover, FRT and post FRT requirements (like extra reactive current support and rate limited return of active power) are executed by GSC control. While, FRT DC voltage regulation is performed by either WPPSC or

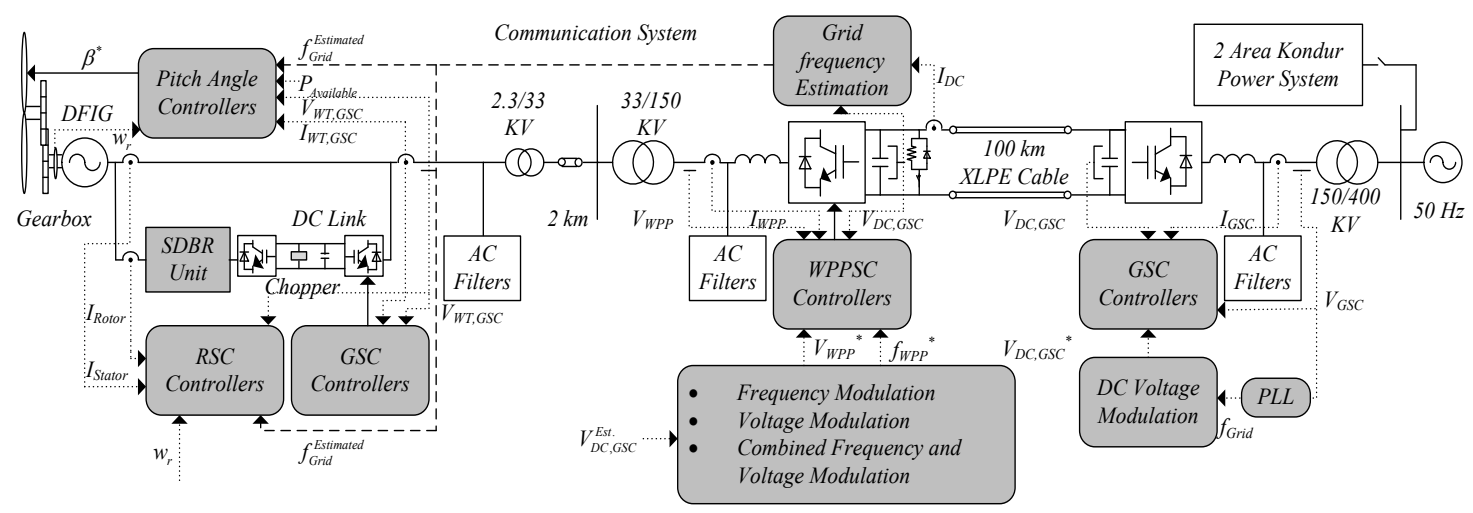

Fig. 1 DFIG based offshore wind farm connected to VSC-HVDC link

DC link chopper. The DC voltage reference is determined considering measured onshore grid frequency. It is to communicate onshore frequency to the offshore converter.

$$
V_{D C, G S C}^{*}=V_{D C 0}+K_{d c f}\left(f_{\text {grid }}-f_{0}\right)
$$

Taking estimated maximum German grid frequency $(52.7 \mathrm{~Hz})$ and maximum permissible DC link Voltage (1.2 $\mathrm{pu}$ ) into account, $\mathrm{K}_{\text {dcf }}$ is taken as $\mathrm{K}_{\mathrm{dcf}}=0.2 / 0.054 \mathrm{pu}$. The reference DC voltage value is tracked by a PI controller that is tuned considering $0.05 \mathrm{~s}$ as time constant. Reactive current reference is determined by employing 
an AC voltage controller in normal operating condition. On the other hand, the reactive current reference is determined by Eq. 2 in FRT operation.

$$
i_{q, G S C}^{*}=K_{i q}\left(V_{\text {grid }}-V_{0}\right)
$$

The $\mathrm{K}_{\mathrm{iq}}$ is set to $2 p u / \Delta V$ according to GC provisions. $\mathrm{I}_{\mathrm{d}}{ }^{*}$ and $\mathrm{I}_{\mathrm{q}}{ }^{*}$ references are tracked by an internal current control loop with the bandwidth of $200 \mathrm{rad} / \mathrm{s}$ and appropriate feedforward compensation terms (Zhang et al., 2015). Priority of current capacity sharing is given to reactive component in FRT operation. Moreover, a timer is turned ON (for $5.2 \mathrm{~s}$ ) to limit the rate of post-fault active power increase to $0.2 \mathrm{pu} / \mathrm{s}$ and its final value to last measured data. The controller structure is shown in Fig. 3.

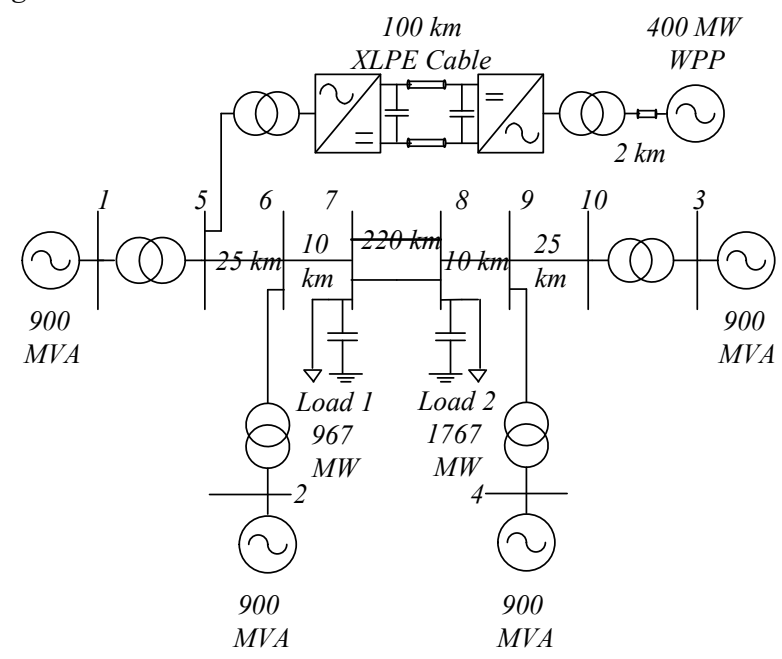

Fig. 2 Kondurs two area power system and its connected offshore wind farm

\subsubsection{WPPSC}

The main role of the WPPSC is to provide the wind farm an AC voltage with fixed amplitude, frequency, and angle. Therefore, it acts as a slack bus by absorbing and injecting WTs generated power to HVDC link. AC voltage amplitude controller determines the $d$-axis voltage reference, while, q- axis reference value is set to zero to provide zero reference angle. The reference $\mathrm{AC}$ voltage amplitude and/or frequency values are internationally varied proportional to GSC side DC voltage magnitude (that will be estimated) during FRT operation or frequency events. However, those are left intact if a communication infrastructure is utilized. The controller structure is depicted in Fig. 4.

In frequency modulation (second approach):

$V_{W P P}^{*}=V_{W P P 0}$

$f_{W P P}^{*}=f_{0}+K_{f d c}\left(V_{D C, G S C}^{E s t .}-V_{D C 0}\right)$

in which:

$V_{D C, G S C}^{E s t .}=V_{D C, W P P S C}-R_{H V D C} \cdot I_{D C}$

To impose an identical event (with respect to onshore grid event), the $K_{\mathrm{fdc}}$ value is set to be $\mathrm{K}_{\mathrm{fdc}}=1 / \mathrm{K}_{\mathrm{dcf}}=0.27$. On the other hand, in voltage modulation (third approach):

$V_{W P P}^{*}=V_{W P P 0}+K_{v d c}\left(V_{D C, G S C}^{E s t .}-V_{D C 0}\right)$

$f_{W P P}^{*}=f_{0}$

The $\mathrm{K}_{\mathrm{vdc}}=-2$ is selected to in order to preserve $\mathrm{AC}$ voltage amplitude in the acceptable range of $\Delta V_{W P P}=K_{v d c} \cdot K_{d c f} \Delta f_{\text {grid }}=-0.03 p u$ even in maximum steady state onshore grid frequency deviation $( \pm 0.2 \mathrm{~Hz}$ for German grid (D'iaz-Gonz'alez et al., 2016)).

In hybrid frequency and voltage modulation approach (fourth approach), the main idea is to discriminate fast and slow dynamics to preserve conventional control structure for slow dynamics and trigger hybrid voltage and frequency modulation for fast dynamics. The German GC indicates $\pm 0.8 \mathrm{~Hz}$ (D'iazGonz'alez et al., 2016) as the maximum transient frequency deviation that will be slowly

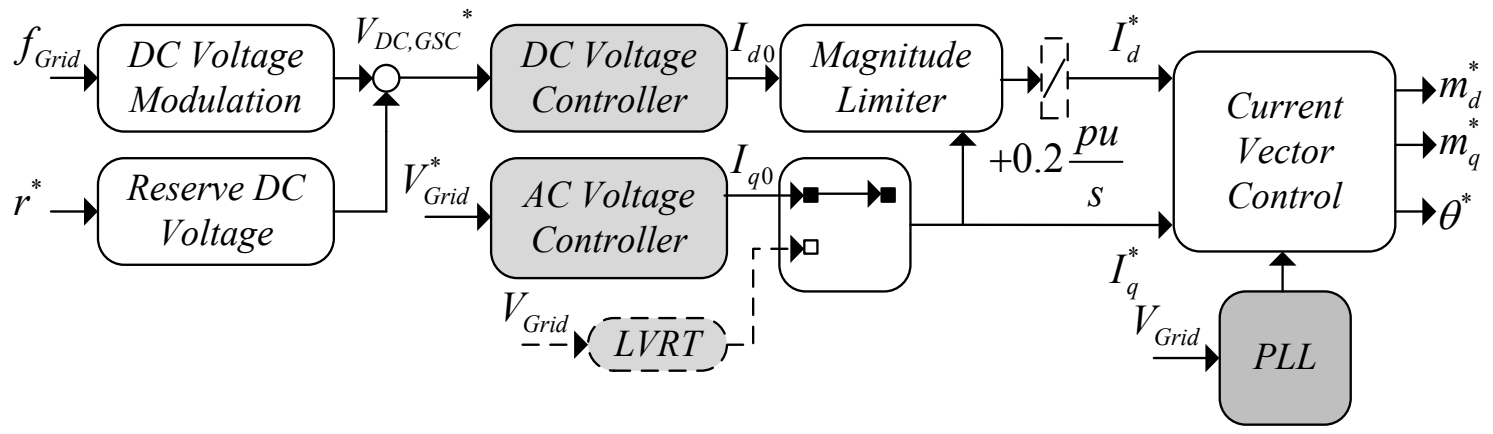

Fig. 3 HVDC GSC controller structure

reflected on HVDC link voltage through GSC controller. However, a fast DC voltage rise is expected in FRT operation. Therefore, it is possible to utilize a high pass filter (with its time constant to be between $[2 \pi 0.5-2 \pi 2.5] \mathrm{Rad} / \mathrm{s})$ in order to perform the discrimination. The hybrid modulation and a timer are triggered (for $5.2 \mathrm{~s}$ which is the maximum time required by protection system and the process of returning to the previous operating point) if the high-pass filter output passes $\Delta V_{D C}=K_{d c f} \Delta f_{\text {grid }}=+0.06 p u$. Therefore, only frequency modulation loop is active in frequency events:

$$
\begin{aligned}
& V_{W P P}^{*}=V_{W P P 0} \\
& f_{W P P}^{*}=f_{0}+K_{f d c}\left(V_{D C, G S C}^{E s t .}-V_{D C 0}\right)
\end{aligned}
$$

While both voltage and frequency modulation loops are active in FRT operation: 


$$
\begin{aligned}
& V_{W P P}^{*}=V_{W P P 0}+K_{v d c}\left(V_{D C, G S C}^{E s t .}-V_{D C 0}\right) \\
& f_{W P P}^{*}=f_{0}+K_{f d c}\left(V_{D C, G S C}^{E s t .}-V_{D C 0}\right)
\end{aligned}
$$

$\mathrm{K}_{\mathrm{fdc}}$ and $\mathrm{K}_{\mathrm{vdc}}$ coefficients are calculated based on previous arguments. To satisfy ROCOF limitation, the corresponding block is activated in Fig. 4.

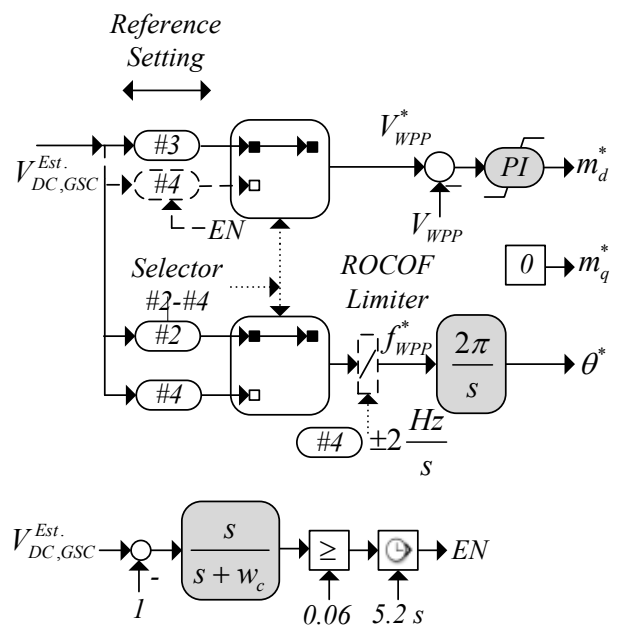

Fig. 4 HVDC WPPSC controller structure

Communication-based approach transfers the result of Eq. 4 and Eq. 3 to DFIG RSC and pitch angle controllers through fibre optics considering communication delays (first approach) (Nanou and Papathanassiou, 2015). Finally, in DC link chopper based approach (fifth approach), the voltage amplitude and frequency references are left intact as in communication-based approach:

$$
\begin{aligned}
& V_{W P P}^{*}=V_{W P P 0} \\
& f_{W P P}^{*}=f_{0}
\end{aligned}
$$

\subsection{DFIG control}

\subsubsection{RSC control}

The main role of DFIGs RSC is the independent regulation of $\mathrm{d}$ and $\mathrm{q}$-axis rotor current employing stator flux oriented control ( $\mathrm{Hu}$ et al., 2011). To increase the accuracy of voltage modulation approach, the RSC is controlled to ensure unity power factor operation of the whole DFIG and corresponding high-pass filters. Hence, the DFIG magnetization current is provided by RSC along with high-pass filter. $d$ - axis rotor current reference is determined by Maximum Power Point Tracking (MPPT) controller. MPPT unit tracks the optimum speed (which is determined by wind speed measurement and passing the result through a lowpass filter with the time constant of $5 \mathrm{~s}$ ) via DFIG torque control. DFIG power reference is determined by multiplying torque reference and instantaneous speed.

To enable WTs to provide inertial frequency response, supplementary control loops containing proportional and derivate terms (which is implemented with washout filter) are added to increase power system inertia and damping. Therefore, in frequency modulation and communication-based approach:

$$
P_{W T}^{*}=P_{M P P T}-K_{\text {Droop }}^{f} \Delta f_{W P P}-K_{\text {Inertia }}^{f} \frac{d}{d t} \Delta f_{W P P}
$$

The values of $\mathrm{K}^{\mathrm{f}}$ Droop and $\mathrm{K}^{\mathrm{f}}$ Inerta are set to be 20 and 10 according to recommendations of (Lee et al., 2016). An optimal solution is proposed in (Lee et al., 2016) to set those values in order to maximize inertial frequency contribution. $\Delta f_{W P P}$ is calculated by WTs local measurement (except communication-based approach), passing through a low pass filter with the time constant of $0.1 \mathrm{~s}$ to eliminate frequency measurement noises (except communication-based approach) and applying a $0.02 \mathrm{~Hz}$ dead band (D'1az-Gonz'alez et al., 2016). Similarly, in voltage modulation:

$$
P_{W T}^{*}=P_{M P P T}-K_{\text {Droop }}^{V} \Delta V_{W P P}-K_{\text {Inertia }}^{V} \frac{d}{d t} \Delta V_{W P P}
$$

$\mathrm{K}^{\mathrm{V}}$ Droop and $\mathrm{K}^{\mathrm{V}}$ Inerta values and the corresponding dead bands are calculated to provide a similar inertial response in same frequency event considering previous approaches

$\left(K_{\text {Droop }}^{V}=2.66, K_{\text {Inertia }}^{V}=1.33\right.$, Deadzone $\left.=0.003 \mathrm{pu}\right)$. On the other hand, both frequency and voltage magnitude dependent terms in Eq. 9 and Eq. 10 are present in hybrid voltage and frequency modulation $\left(P_{W T}^{*}=P_{M P P T}-K_{\text {Droop }}^{f} \Delta f_{W P P}-K_{\text {lnertia }}^{f} \frac{d}{d t} \Delta f_{\text {WPP }}-K_{\text {Droop }}^{V} \Delta V_{W P P}-K_{\text {lnertia }}^{V} \frac{d}{d t} \Delta V_{\text {WPP }}\right)$.

Finally, the reference power is translated to active current reference and is tracked by internal current control loop with the bandwidth of $333.3 \mathrm{rad} / \mathrm{s}$. Limited output power ramp rate $( \pm 0.45 \mathrm{pu} / \mathrm{s}$, except for FRT operational), minimum and maximum output power [$0.05 \mathrm{pu}$ to $1 \mathrm{pu}$ ] and accurate sharing of converters current capacity between active and reactive components are taken into account (Engelhardt et al., 2011).

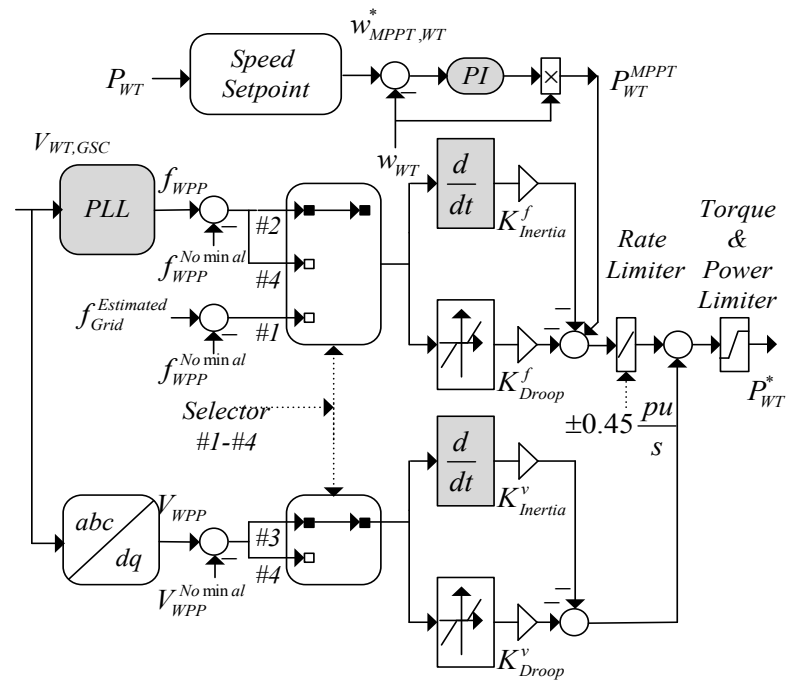

Fig. 5 DFIG RSC controller structure

To discriminate FRT operation from frequency events, maximum estimated transient frequency for German grid (and its equivalent in voltage modulation) is used. Due to nature of voltage-dependent terms that are to limit the FRT transients in DFIGs rotor current and DC link voltage (Yang et al., 2012), ramp rate limitation is not applied to these terms in voltage and hybrid voltage and frequency modulation.

The control structure is shown in Fig. 5. Lowpass filters in (Miller et al., 2003) are also applied to cancel speed measurement noises, however, is not shown in Fig. 5. 


\subsubsection{GSC control}

The main role of the DFIGs GSC is to regulate DC link voltage and ensuring converters unity power factor operation trough implementing grid voltage oriented vector control (Hu et al., 2011). The control structure is similar to HVDC GSC control with a bandwidth of 333 $\mathrm{rad} / \mathrm{s}$ for internal current controllers.

\subsection{Pitch angle control}

Pitch angle control is comprised of two loops that are sensitive to turbine speed and injected electrical power respectively. In normal operation, it regulates turbines speed at optimal speed, while, it limits the injected power at the nominal value in high wind speeds.

$$
\begin{aligned}
& W_{\text {PitchAngle }}^{*}=W_{M P P T} \\
& P_{\text {PitchAngle }}^{*}=P_{\text {Nomial }}
\end{aligned}
$$

To make WT provide primary frequency response, it should be operated in suboptimal condition (Zhang et al., 2012). Therefore, pitch angle control with modified power reference and same speed reference is utilized. The new power reference is generated with estimation of available wind power (Schneider et al., 2013), (Østergaard et al., 2007), droop type power-frequency curve (5\% for German grid) and $0.2 \mathrm{~Hz}$ dead band for frequency modulation, hybrid voltage and frequency modulation and communication-based approaches:

$$
\begin{aligned}
& W_{\text {PitchAngle }}^{*}=W_{M P P T} \\
& P_{\text {PitchAngle }}^{*}=P_{\text {Available }} \cdot\left(1-K_{\text {Droop }}^{f} \cdot \Delta f_{W P P}\right)
\end{aligned}
$$

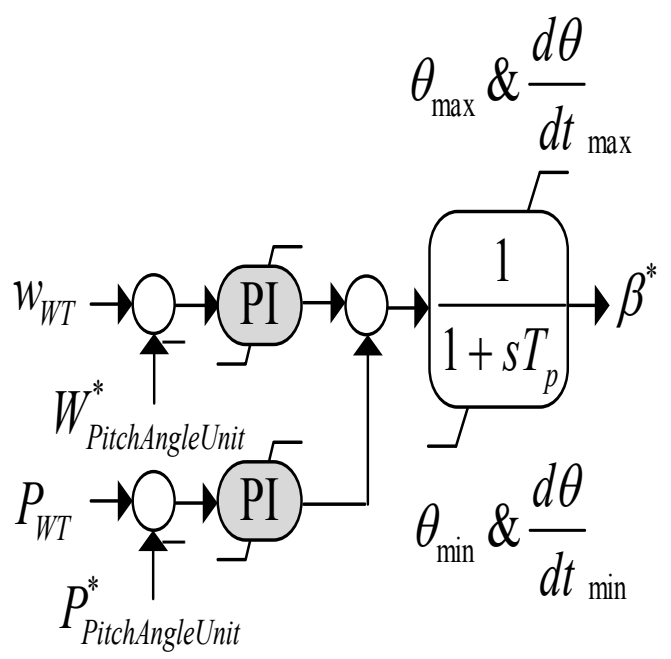

Fig. 6 Pitch angle controller

Similarly, considering a dead band of $0.03 \mathrm{pu}$ and 2.66 droop constant in voltage modulation approach it could be written:

$$
\begin{aligned}
& W_{\text {PitchAngle }}^{*}=W_{M P P T} \\
& P_{\text {PitchAngle }}^{*}=P_{\text {Available }} \cdot\left(1-K_{\text {Droop }}^{V} \Delta V_{W P P}\right)
\end{aligned}
$$

Same ramp rate limitations (as it is applied to DFIG output power) are applied (except in FRT operation) in frequency modulation and communication-based approaches to prevent unnecessary deviation of operating point. The control structure is shown in Fig. 6.

\section{Simulation results}

To demonstrate the adequacy of above-mentioned approaches and comparing them, nonlinear time domain simulations are carried out focusing on FRT operation and frequency events. The generated wind power is taken to be $1 \mathrm{pu}$ and $0.8 \mathrm{pu}$ respectively since adverse effects of voltage dips are maximum at high negative slips (Lopez et al., 2007). The wind speed is taken to be constant during simulations to eliminate possible effects of wind power variations. The results of communicationbased, frequency modulation, voltage modulation, hybrid voltage and frequency modulation and DC link chopper based approaches are shown with magenta, green, red, blue and black lines respectively. The base power is taken to be 400 MVA.

\section{1 FRT operation}

A $200 \mathrm{~ms}$ symmetric fault is applied in $\mathrm{t}=6 \mathrm{~s}$ according to Fig. 7(a). To emphasize on fault period, limited rate of returning to the previous operating point is not taken into account. The 3 phase fault is resulted in $50 \%$ voltage dip and triggered GSC to inject maximum reactive current (-1 pu) to grid according to GC requirements. Therefore, the injected power to the grid is reduced dramatically. The reactive current shown is Fig. 7(c) includes both GSC and AC filters reactive current. The resulted power imbalance is totally dissipated (72.5 MJ) in DC chopper based approach. Hence, wind farm operating points are left intact. In other approaches, DC link overvoltage is resulted in triggering the implemented approach, exhibiting inertial response and subsequent reduction of the injected wind power. Communication of onshore grid status in communication based approach, increase of wind farms frequency to $52.65 \mathrm{~Hz}$ in frequency modulation approach, reduction of wind farm voltage to $0.71 \mathrm{pu}$ and $0.69 \mathrm{pu}$, in voltage modulation and hybrid voltage and frequency respectively and ROCOF limited increase of wind farm frequency to $50.75 \mathrm{~Hz}$ in hybrid approach (Fig. 7(e,f)) have lead to fast decrease of wind farms injected power considering limited permissible range of DFIG to be operated in motor region (Fig. 7(i)). In consequence, (with except frequency modulation approach which is known by the intrinsic delay of frequency measurement and filtering), communication-based, voltage modulation and hybrid modulation approaches have limited the DC overvoltage to $1.15 \mathrm{pu}, 1.17 \mathrm{pu}$, and $1.18 \mathrm{pu}$ respectively. However, despite failure, frequency modulation has limited the dissipated energy to $17.5 \mathrm{MJ}$. The high ramp rate of wind farm frequency variation in frequency modulation approach makes it infeasible. 


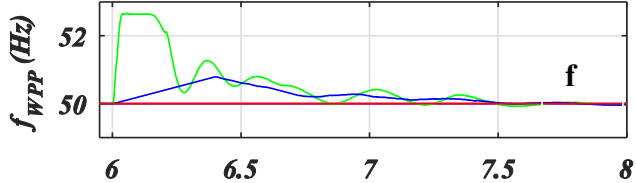

Time (s)
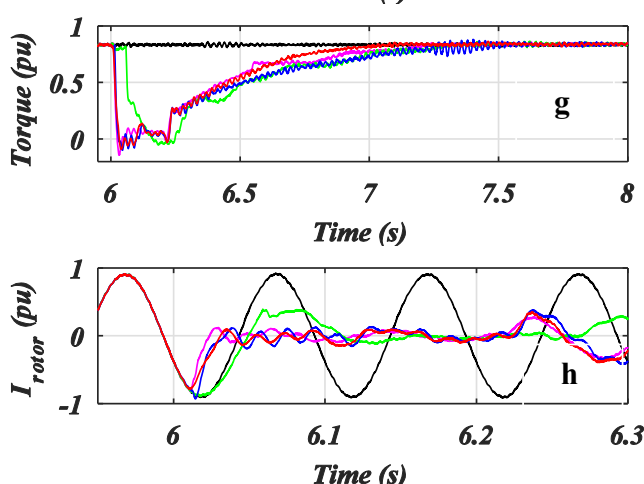

Time (s)
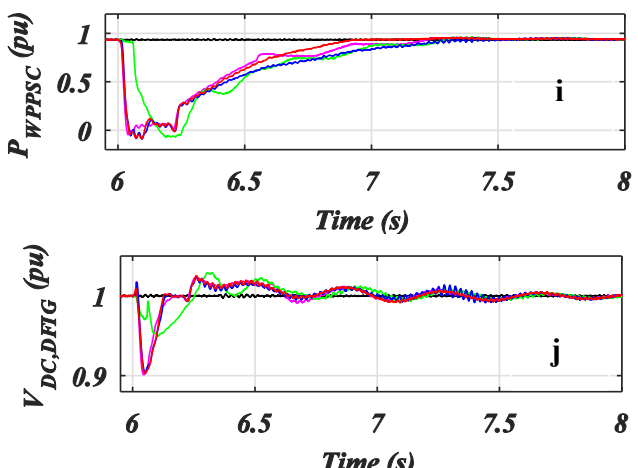
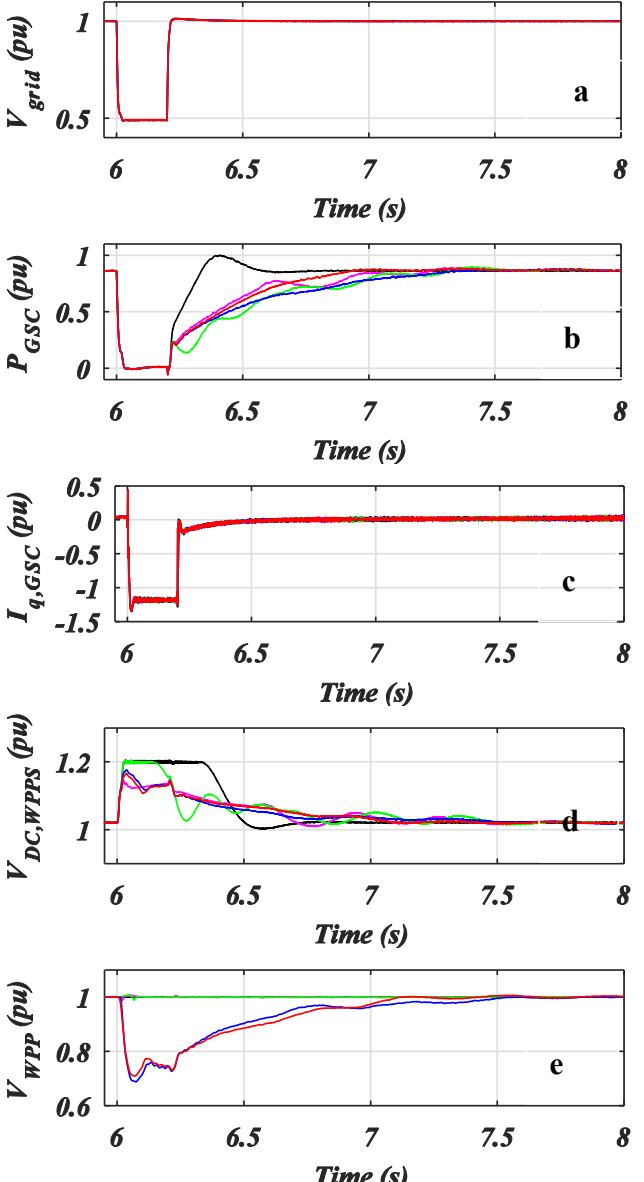

Fig. 7 Response of 5 different approaches to three phase short circuit fault: a) Power system voltage amplitude b) GSC injected power c) q-axis GSC current d) HVDC link voltage e) Wind farm voltage amplitude f) Wind farm frequency g) DFIG torque h) DFIG RSC current i) HVDC WPPSC injected power j) DFIG DC link voltage
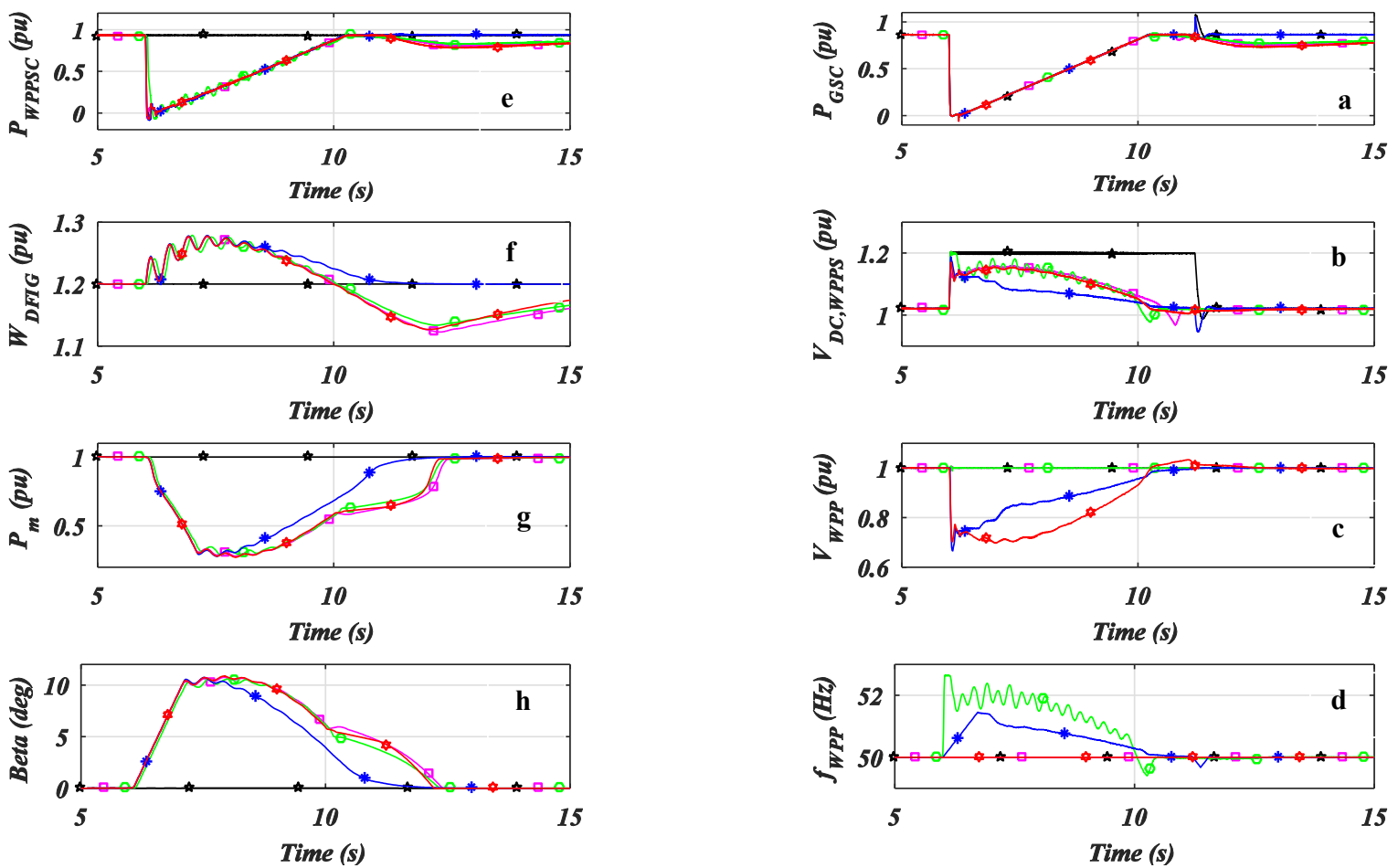

Fig. 8 Response of 5 different approaches to three phase short circuit fault: a) GSC injected power b) HVDC link voltage c) Wind farm voltage amplitude d) Wind farm frequency e) HVDC WPPSC injected power f) DFIG speed g) WT aerodynamic power h) Pitch angle 

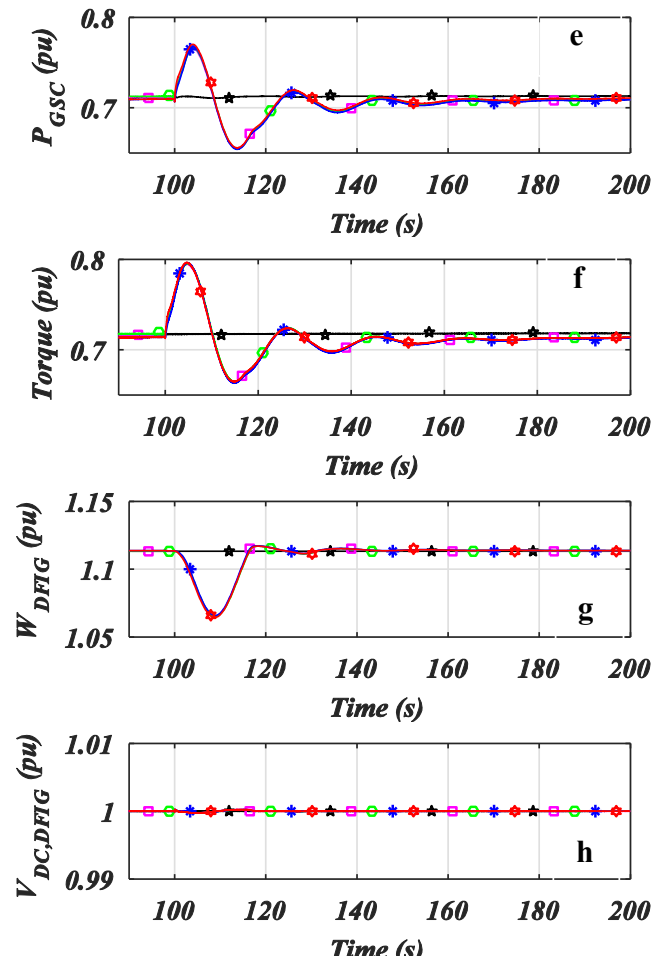

Fig. 9 Response of 5 different approaches to 200 MW load increase: a) Power system frequency b) HVDC link voltage c) Wind farm frequency d) Wind farm voltage amplitude e) GSC injected power f) DFIG torque g) WT speed h) DFIG DC link voltage
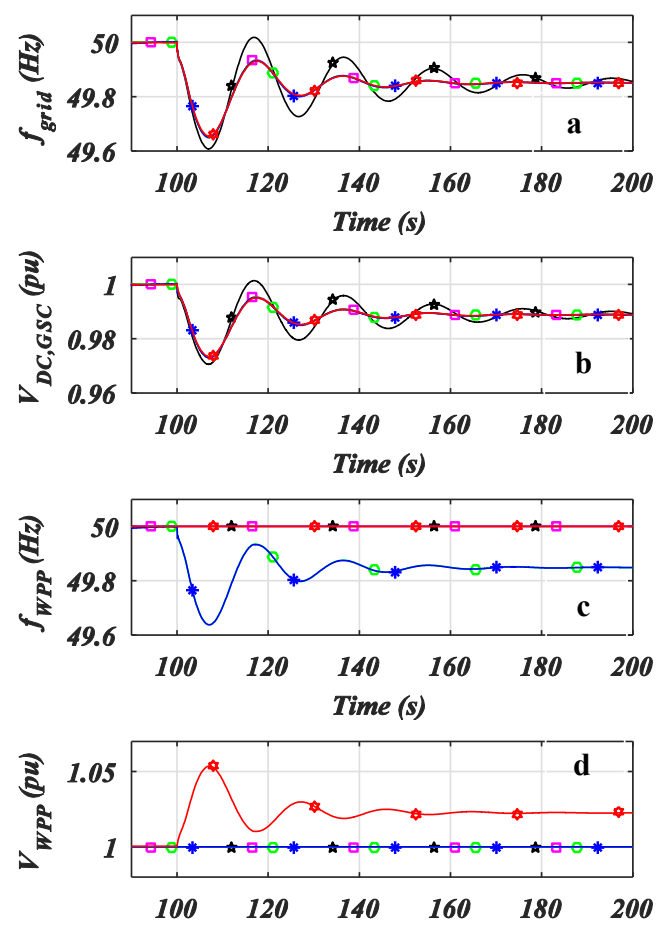

Time (s)
As communication delay is increased to $5 \mathrm{~ms}$, HVDC link over-voltage is limited to $1.18 \mathrm{pu}$. Further increase of communication delay to $10 \mathrm{~ms}, 20 \mathrm{~ms}, 30 \mathrm{~ms}$ and 40 $\mathrm{ms}$ has failed the communication system based approach in limiting the HVDC link over-voltage to $1.2 \mathrm{pu}$. Therefore, DC link chopper has dissipated the power imbalance (0.52 MJ, 2.47 MJ, 3.92 MJ and 5.45 MJ respectively). However, the dissipated energy is reduced significantly in comparison with DC chopper based (fifth) approach.

Limited voltage drop in the wind farm is due to the presence of inertial control loops and leads to minimal DFIG electrical torque stress with an amplitude of oscillations limited to $0.15 \mathrm{pu}$ (Fig. $7(\mathrm{~g})$ ) and elimination of rotor overcurrents (Fig. 7(h)). Therefore, protection devices (DC link chopper and series braking unit) are not triggered. The power imbalance is stored as kinetic energy at WTs masses in all approaches (except in DC link chopper based approach) (Fig. 8(f)). The presence of torsional oscillation due to the soft shaft is visible.

The above scenario is simulated anew taking limited rate of returning to previous operating point into account. The limited ramp rate is lead to the prolonged presence of DC overvoltage (approximately $5.2 \mathrm{~s}$ ). This period of time is long enough to trigger primary frequency response and hence the action of pitch controller to a permanent decrease of wind power (according to German GC). As DC link overvoltage level increases, the deviation from previous operating point increase. Consequently, a part of wind farms injected power in returning to the previous operating point is absorbed from WTs masses kinetic energy (Fig. 8(f)). As this absorbed energy is recovered after reaching the previous operating point, a consequent frequency event is expected (Fig. 8(e)). The hybrid modulation approach is effectively reduced wind farms injected power due to simultaneous modulation of voltage amplitude and frequency and action of two independent inertial loops sensitive to them. In consequence, the corresponding DC over voltage level is minimum.

Moreover, the ROCOF limitation makes pitch angle unit to slowly provide primary frequency and consequent minimum deviation from the operating point. Therefore, the adverse effects of hybrid modulation is minimum (except in comparison with DC chopper based approach)

\section{1 Frequency response capability}

To evaluate under frequency response of the VSC-HVDC connected wind farm, a $200 \mathrm{MW}$ load is suddenly added to bus 7 (Fig. 2). The consequent power system frequency drop is reflected in HVDC link voltage through modulation of DC link voltage reference (Fig. 9(b)). The reflected DC Link under voltage has lead to wind farms voltage amplitude reference variation (in voltage modulation approach) and frequency reference variation (in frequency and hybrid modulation) to emulate onshore grid variations in Fig. 9(d) and Fig. 9(c). The communication-based approach has transmitted the DC under voltage to WTs RSC and pitch angle controllers. As a result, WTs have provided inertial response in order to reduce the magnitude of oscillations and improving power system damping. 

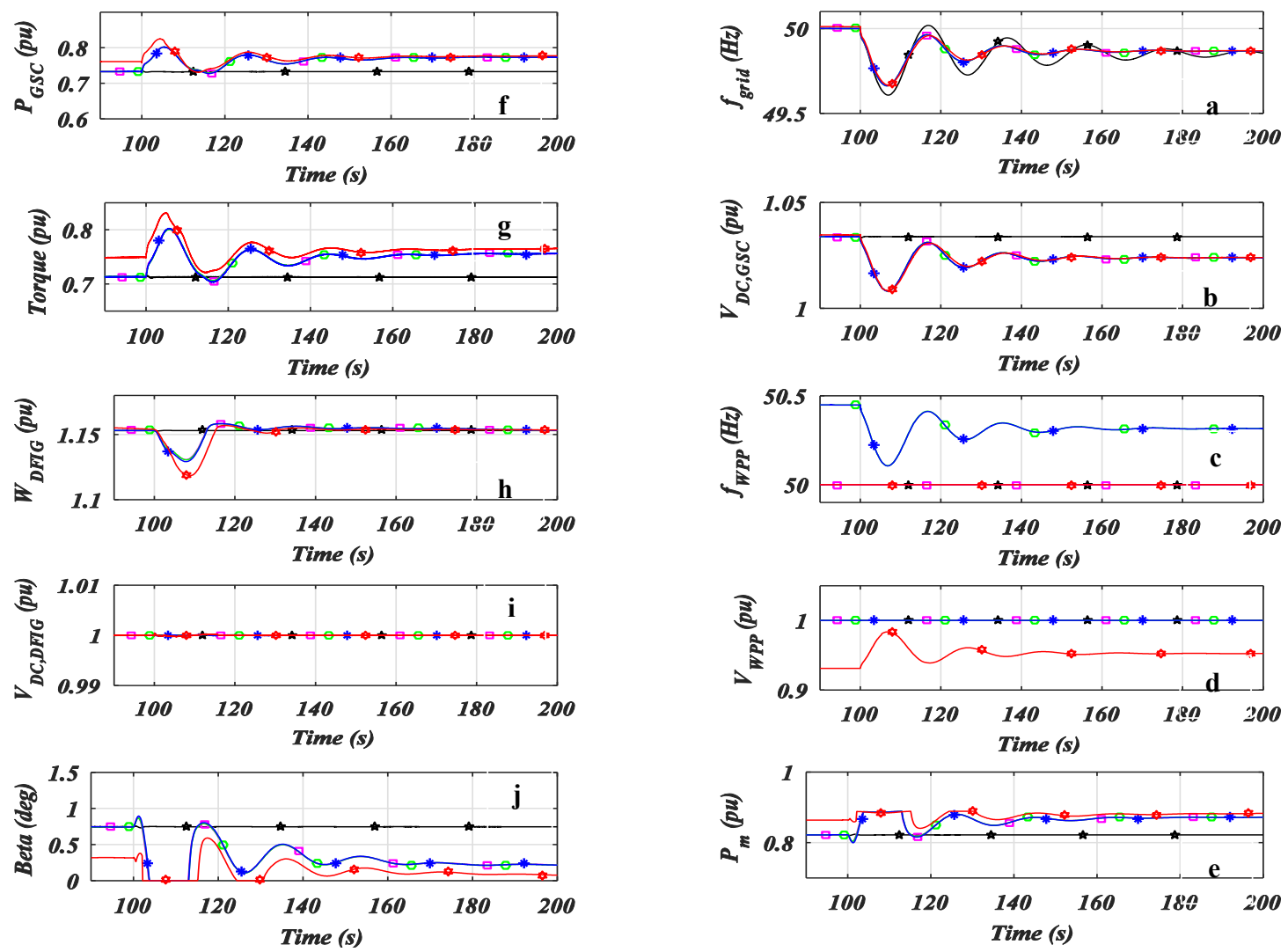

Fig. 10 Response of 5 different approaches to 200 MW load increase with \%10 reserve: a) Power system frequency b) HVDC link voltage c) Wind farm frequency d) Wind farm voltage amplitude e) WT aerodynamic power f) GSC injected power g) DFIG torque h) WT speed i) DFIG DC link voltage j) Pitch angle
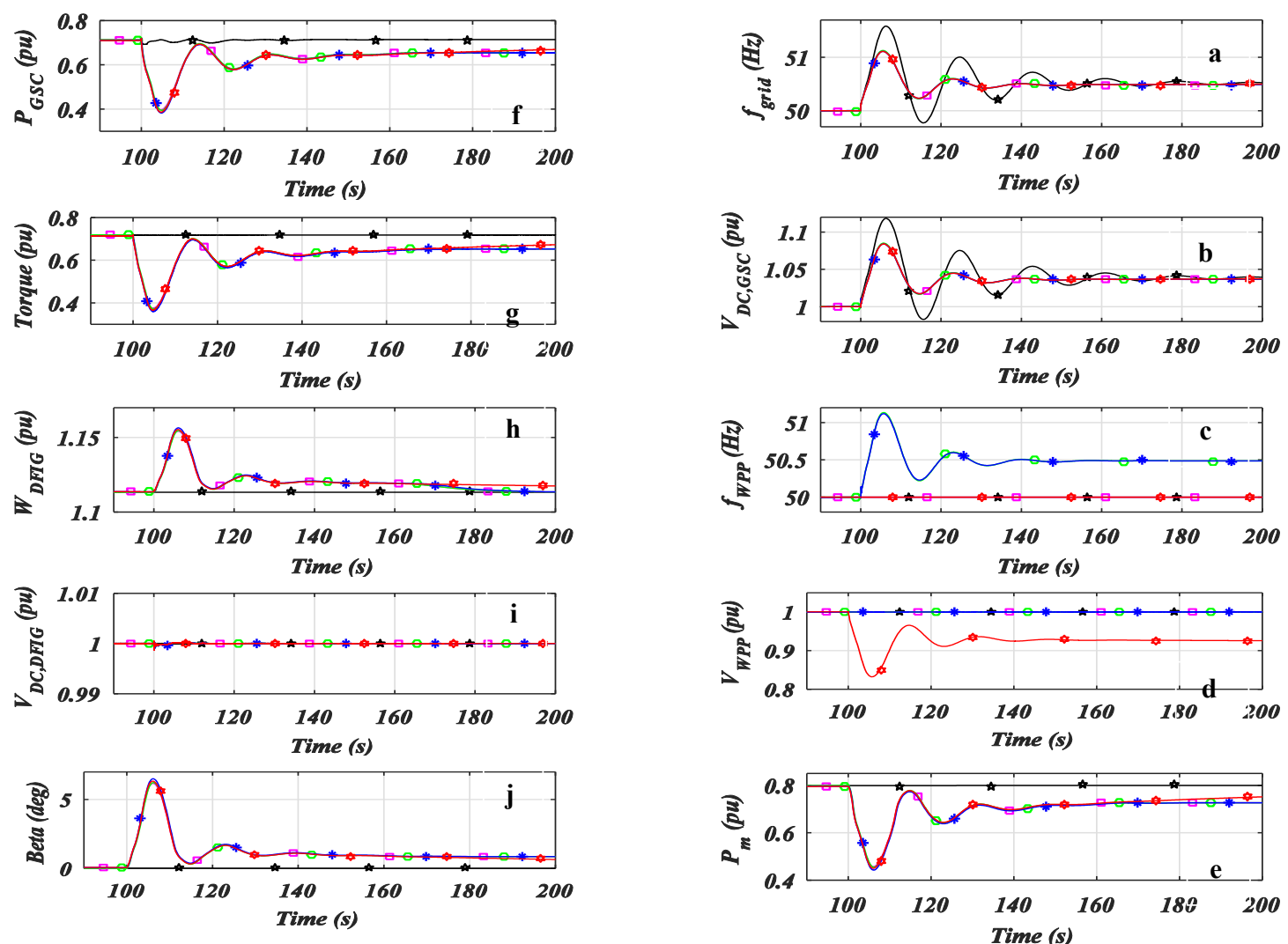

Fig. 11 Response of 5 different approaches to 600 MW load decrease: a) Power system frequency b) HVDC link voltage c) Wind farm frequency d) Wind farm voltage amplitude e) WT aerodynamic power f) GSC injected power g) DFIG torque h) WT speed i) DFIG DC link voltage j) Pitch angle 
This has done by transient increase of injected power (up to 0.06 pu in Fig. 9(e)) in first several seconds of load increment. The sluggish dynamics of power system have lead to a similar response to a similar response (with negligible errors) in all approaches (with except DC link chopper based approach) in providing inertial frequency response. Therefore, the maximum frequency drop in reduced $10.25 \%$ and the power system damping is improved significantly. However, final frequency deviation $(49.85 \mathrm{~Hz})$ is left intact (Fig. 9(a)).

To reduce final frequency deviation, $10 \%$ reserve is assumed and applied by appropriate HVDC link voltage reference increment (Fig. 10(b)), subsequent implementing of (frequency, voltage and hybrid) modulation approaches or communication-based approach, and pitch angle controllers actions. Therefore, in a similar frequency event, the wind farm has provided simultaneous inertial and primary frequency response. This has done by a transient increase of injected power up to $0.07 \mathrm{pu}$ (Fig. 10(f)) and permanent increase of it up to $0.04 \mathrm{pu}$. In consequent, the maximum transient frequency drop and steady state frequency drop are reduced $15.38 \%$ and $13.33 \%$ respectively and power system damping is improved significantly (Fig. 10(a)).

To evaluate over frequency response, a $600 \mathrm{MW}$ load is suddenly disconnected from bus 7 (Fig 2) considering $0.2 \mathrm{~Hz}$ dead band in German GC. The consequent over frequency has reflected as HVDC link overvoltage (Fig. 11(b)). Hence, the voltage amplitude or/and frequency have varied according to implemented approach (Fig. 11(d) and Fig. 11(c)) to mimic onshore frequency oscillations. In consequence, the inertial and primary frequency response have been provided by maximum transient and permanent reduction of injected power up to $0.32 \mathrm{pu}$ and $0.06 \mathrm{pu}$ respectively (Fig. 11-f). Hence, the maximum transient and permanent frequency increase are reduced by $29.74 \%$ and $5.88 \%$ respectively. Moreover, the power system damping is increased significantly.

\section{Conclusions}

Adaptation of VSC-HVDC connected DFIG based offshore wind farm is investigated in a univalent control structure based on inertial and primary frequency response. The practical restrictions are taken into account. Considering FRT operation, communicationbased, voltage and hybrid modulation have been successful in the fast reduction of wind farms injected power in several milliseconds, and hence, in limiting DC link over-voltage to $1.2 \mathrm{pu}$. However, this ability is lost in communication-based approach as communication delays increase. On the other hand, frequency modulation based approach has been failed to adapt FRT GC compatibility due to the presence of inherent delays of frequency measurement and filtering. Moreover, violation of ROCOF limitation restricts its practical application. The prolonged presence of DC link over-voltage has been long enough to trigger primary frequency response and consequent deviation from the previous operating point. Therefore, a part of WTs kinetic energy have been used to return to the previous operating point, that results in subsequent frequency event. Meanwhile, hybrid modulation has had minimum adverse effects due to minimum DC link overvoltage and limited ROCOF (and subsequent slow triggering of primary frequency response).

Considering frequency events, slow dynamics of power system oscillation have lead to similar (with negligible errors) results implementing all approaches (except DC link based approach). Meanwhile, the free current capacity of DFIGs RSC is increased during under frequency events implementing voltage modulation due to the increased wind farm voltage. Therefore extra providing of inertial and primary frequency response is possible that will be explored in authors future research.

\section{Appendix}

5 MW DFIG Wind Turbine: Rated voltage: $2300 \mathrm{~V}$, Area = $12469 \mathrm{~m} 2$, Rated Wind Speed=11.68 m/s, Rated Speed=1.46 $\mathrm{rad} / \mathrm{s}, \mathrm{Hr}=4.32 \mathrm{~s}$, gearbox ratio: $1: 129.09, \mathrm{~K}=211.13$ p.u., $\mathrm{D}=$ 1.84 p.u., $\mathrm{Hg}=0.62$ s., $\mathrm{Rs}=0.023$ p.u, $R r^{\prime}=0.016$ p.u., $\mathrm{X}_{\sigma \mathrm{s}}=0.18$ p.u., $\mathrm{Xor}{ }^{\prime}=0.16$ p.u., $\mathrm{Xm}=2.9$ p.u., $\mathrm{CDC}_{\mathrm{DC}}=5800 \mathrm{uF}, \mathrm{DC}$ Voltage $=4200 \mathrm{~V}, \mathbf{2 . 3 / 3 3}$ KV Transformer: $\mathrm{S}=500 \mathrm{MVA}, \mathrm{X}=0.05$ p.u, Efficiency $=99.5 \%$, Wind Farm Cable: $R=0.0496$ ohms, $\mathrm{L}=14.4 \mathrm{mH}, \mathbf{3 3 / 1 5 0} \mathrm{KV}$ Transformer: $\mathrm{S}=500 \mathrm{MVA}, \mathrm{X}=0.07 \mathrm{p} . \mathrm{u}$, Efficiency $=99.5 \%$, Phase Reactor: Sbase $=430.8$ MVA, $X=0.19$ pu, $R=0.025$ pu, HVDC Converter: $S=430.8$ MVA, $f_{\text {switching }}=1650$ $\mathrm{Hz}$, Three Level NPC, $\mathrm{C}_{\mathrm{DC}}=192 \mathrm{uF}$, AC Filters: 86.1 MVAR, DC Line: $100 \mathrm{~km}, \mathrm{R}=0.027 \mathrm{ohm} / \mathrm{km}, \mathrm{L}=0.223 \mathrm{mH} / \mathrm{km}, \mathrm{C}=0.141$ $\mathrm{uF} / \mathrm{km}, \mathrm{V}_{\mathrm{DC}}=300 \mathrm{KV}$

\section{References}

Adeuyi, O.D., Cheah-Mane, M., Liang, J., Livermore, L., Mu, Q., 2015. Preventing DC over-voltage in multi-terminal HVDC transmission. CSEE Journal of Power and Energy Systems $1,86-94$.

Association, T.E.W.E., 2016. Wind in power, 2015 European statistics, in: Pineda, I. (Ed.).

Chaudhary, S.K., Teodorescu, R., Rodriguez, P., Kj, P.C., x00E, 2009. Chopper controlled resistors in VSC-HVDC transmission for WPP with full-scale converters, 2009 IEEE PES/IAS Conference on Sustainable Alternative Energy (SAE), pp. 1-8.

D'iaz-Gonz'alez, F., Sumper, A., Gomis-Bellmunt, O., 2016. Energy Storage in Power Systems. John Wiley \& Sons, Ltd.

Energinet, 2014. Environmental report for Danish electricity and CHP: summary of the status year.

Engelhardt, S., Erlich, I., Feltes, C., Kretschmann, J., Shewarega, F., 2011. Reactive Power Capability of Wind Turbines Based on Doubly Fed Induction Generators. IEEE Transactions on Energy Conversion 26, 364-372.

ENTSOE, (2015). Network Code on Requirements for Grid Connection Applicable to all Generators (RfG), in: Electricity, E.N.o.T.S.O.f. (Ed.). European Union Official Journal

Erlich, I., Feltes, C., Shewarega, F., 2014. Enhanced Voltage Drop Control by VSC-HVDC Systems for Improving Wind Farm Fault Ridethrough Capability. IEEE Transactions on Power Delivery 29, 378-385.

Feltes, C., Wrede, H., Koch, F.W., Erlich, I., 2009. Enhanced Fault Ride-Through Method for Wind Farms Connected to the Grid Through VSC-Based HVDC Transmission. IEEE Transactions on Power Systems 24, 1537-1546.

Foster, S., Xu, L., Fox, B., 2008. Control of an LCC HVDC system for connecting large offshore wind farms with special consideration of grid fault, Power and Energy 
Society General Meeting - Conversion and Delivery of Electrical Energy in the 21st Century, 2008 IEEE, pp. 1-8.

García, C.A., Fernández, L.M., Jurado, F., 2015. Evaluating reduced models of aggregated different doubly fed induction generator wind turbines for transient stabilities studies. Wind Energy 18, 133-152.

Hu, J., Nian, H., Xu, H., He, Y., 2011. Dynamic Modeling and Improved Control of DFIG Under Distorted Grid Voltage Conditions. IEEE Transactions on Energy Conversion 26, 163-175.

Hu, X., Liang, J., Rogers, D.J., Li, Y., 2013. Power Flow and Power Reduction Control Using Variable Frequency of Offshore AC Grids. IEEE Transactions on Power Systems 28, 3897-3905.

Jonkman, J., Butterfield, S., Musial, W., Scott, G., 2009. Definition of a 5-MW Reference Wind Turbine for Offshore System Development in: Energy, U.S.D.o. (Ed.). National Renewable Energy Laboratory.

Junyent-Ferr, A., Pipelzadeh, Y., Green, T.C., 2015. Blending HVDC-Link Energy Storage and Offshore Wind Turbine Inertia for Fast Frequency Response. IEEE Transactions on Sustainable Energy 6, 1059-1066.

Klein, M., Rogers, G.J., Kundur, P., 1991. A fundamental study of inter-area oscillations in power systems. IEEE Transactions on Power Systems 6, 914-921.

Lee, J., Muljadi, E., Srensen, P., Kang, Y.C., 2016. Releasable Kinetic Energy-Based Inertial Control of a DFIG Wind Power Plant. IEEE Transactions on Sustainable Energy 7, 279-288.

Liu, H., Chen, Z., 2015. Contribution of VSC-HVDC to Frequency Regulation of Power Systems With Offshore Wind Generation. IEEE Transactions on Energy Conversion 30, 918-926.

Lopez, J., Sanchis, P., Roboam, X., Marroyo, L., 2007. Dynamic Behavior of the Doubly Fed Induction Generator During Three-Phase Voltage Dips. IEEE Transactions on Energy Conversion 22, 709-717.

Lu, H., Yuan, Z., Wei, L., Kerkman, R., Lukaszewski, R., Ahmed, A.M., 2013. Double Fed Iduction Generator (DFIG) Converter And Method For Improved Grid Fault Ridethrough, in: Office, U.S.P.a.T. (Ed.). Rockwell Automation Technologies, Inc., US.

Miao, Z., Fan, L., Osborn, D., Yuvarajan, S., 2010. Wind Farms With HVdc Delivery in Inertial Response and Primary Frequency Control. IEEE Transactions on Energy Conversion 25, 1171-1178.

Miller, N.W., Price, W.W., Sanchez-Gasca, J.J., 2003. Dynamic Modeling of GE 1.5 and 3.6 Wind Turbine-Generators. General Electric International, Inc., U.S.A.

Mohseni, M., Islam, S.M., 2012. Review of international grid codes for wind power integration: Diversity, technology and a case for global standard. Renewable and Sustainable Energy Reviews 16, 3876-3890.

Nanou, S., Papathanassiou, S., 2015. Evaluation of a communication-based fault ride-through scheme for offshore wind farms connected through high-voltage DC links based on voltage source converter. IET Renewable Power Generation 9, 882-891.

Nanou, S.I., Papathanassiou, S.A., 2016. Grid Code Compatibility of VSC-HVDC Connected Offshore Wind Turbines Employing Power Synchronization Control. IEEE Transactions on Power Systems PP, 1-9.

Nanou, S.I., Patsakis, G.N., Papathanassiou, S.A., 2015. Assessment of communication-independent grid code compatibility solutions for VSC-HVDC connected offshore wind farms. Electric Power Systems Research 121, 38-51.

Nasiri, M., Milimonfared, J., Fathi, S.H., 2015. A review of lowvoltage ride-through enhancement methods for permanent magnet synchronous generator based wind turbines. Renewable and Sustainable Energy Reviews 47, 399-415.
Østergaard, K.Z., Brath, P., Stoustrup, J., 2007. Etimation of Effective Wind Speed. Journal of Physics: Conference Series 75 .

Phulpin, Y., 2012. Communication-Free Inertia and Frequency Control for Wind Generators Connected by an HVDC-Link. IEEE Transactions on Power Systems 27, 1136-1137.

Pipelzadeh, Y., Chaudhuri, B., Green, T.C., 2012. Inertial response from remote offshore wind farms connected through VSC-HVDC links: A Communication-less scheme, 2012 IEEE Power and Energy Society General Meeting, pp. 1-6.

Ramtharan, G., Arulampalam, A., Ekanayake, J.B., Hughes, F.M., Jenkins, N., 2009. Fault ride through of fully rated converter wind turbines with $\mathrm{AC}$ and $\mathrm{DC}$ transmission. IET Renewable Power Generation 3, 426-438.

Red Eléctrica de España, S.A.U., 2015. The Spanish Electricity System: Preliminary report

Sanz, I.M., Chaudhuri, B., Strbac, G., 2015. Inertial Response From Offshore Wind Farms Connected Through DC Grids. IEEE Transactions on Power Systems 30, 1518-1527.

Schneider, D., Küster, K.K., Siefert, M., Fraunhofer, M.S., 2013. Available Active Power Estimation for the Provision of Control Reserve by Wind Turbines, European Wind Energy Conference and Exhibition (EWEC), Vienna, Austria.

Shoulaie, A., Jafarabadi, S.E., 2005. Analysis, modelling and simulation of HVDC transmission line internal overvoltages Journal of Iranian Association of Electrical and Electronics Engineers 1, 11-22.

Silva, B., Moreira, C.L., Leite, H., Pe, J.A., x00E, as, L., 2014. Control Strategies for AC Fault Ride Through in Multiterminal HVDC Grids. IEEE Transactions on Power Delivery 29, 395-405.

Silva, B., Moreira, C.L., Seca, L., Phulpin, Y., Lopes, J.A.P., 2012. Provision of Inertial and Primary Frequency Control Services Using Offshore Multiterminal HVDC Networks. IEEE Transactions on Sustainable Energy 3, 800-808.

Tsili, M., Papathanassiou, S., 2009. A review of grid code technical requirements for wind farms. IET Renewable Power Generation 3, 308-332.

Xu, L., Yao, L., Sasse, C., 2007. Grid Integration of Large DFIGBased Wind Farms Using VSC Transmission. IEEE Transactions on Power Systems 22, 976-984.

Yang, L., Xu, Z., Ostergaard, J., Dong, Z.Y., Wong, K.P., 2012. Advanced Control Strategy of DFIG Wind Turbines for Power System Fault Ride Through. IEEE Transactions on Power Systems 27, 713-722.

Yazdi, S.S.H., Fathi, S.H., Monfared, J.M., Amiri, E.M., 2014. Optimal operation of multi terminal HVDC links connected to offshore wind farms, Electrical Engineering/Electronics, Computer, Telecommunications and Information Technology (ECTI-CON), 2014 11th International Conference on, pp. 1-6.

Zhang, X., Wu, Z., Hu, M., Li, X., Lv, G., 2015. Coordinated Control Strategies of VSC-HVDC-Based Wind Power Systems for Low Voltage Ride Through. Energies 8, 72247242

Zhang, Z.S., Sun, Y.Z., Lin, J., Li, G.J., 2012. Coordinated frequency regulation by doubly fed induction generatorbased wind power plants. IET Renewable Power Generation 6, 38-47. 